\title{
An assessment of the terrestrial mammal communities in forests of Central Panama, using camera-trap surveys
}

\author{
*Ninon Meyer ${ }^{1,2,3}$, Helen J. Esser ${ }^{1,2}$, Ricardo Moreno ${ }^{1,3}$, Frank van Langevelde ${ }^{2}$,Yorick Liefting ${ }^{1,2}$, \\ David Ros Oller ${ }^{1,2}$, Chantal B.F. Vogels ${ }^{1,2}$, Andrew D. Carver ${ }^{4,5}$, Clayton K. Nielsen ${ }^{4}$ and Patrick A. \\ Jansen $^{1,2}$
}

1. Smithsonian Tropical Research Institute, Apartado 0843-03092, Balboa, Ancon, Panama

2. Department of Environmental Sciences, Resource Ecology Group, Wageningen University, P.O.

Box 47, 6700 AA, Wageningen, The Netherlands

3. Yaguara Panamá - Sociedad Panameña de Biología, San Francisco, Panama

4. Department of Forestry and Cooperative Wildlife Laboratory, Southern Illinois University, Carbondale, IL, USA

5. Asociación Panamericana para la Conservación, Gamboa Resort, 0265, Colón, Panamá

*Corresponding author: ninonmeyer@gmail.com

1

(C) 2015. This manuscript version is made available under the Elsevier user license 


\begin{abstract}
The Isthmus of Panama, part of the planet's third largest megadiversity hotspot, and connecting the faunas of North and South America, has lost more than half of its forest partly due to economic development. However, it is unknown to what degree the remaining forest, which is fragmented and subject to poaching, still supports the wildlife diversity found in intact forests. Here, we use camera-trap surveys to assess whether forests in Central Panama, the narrowest and most disturbed portion of the Isthmus, still have intact communities of medium- and large-bodied terrestrial mammals. During 2005-2014, we collected camera-trap survey data from 15 national parks and forest fragments on both sides of the Panama Canal, and compared these to similar data from two sites in the intact Darién National Park in Eastern Panama, the nearest available reference. We found that most sites in Central Panama - including some of the national parks - had lower mammal species richness and evenness than the reference sites, and less structurally-complex mammal communities. Forests in Central Panama had little or no apex predators and large terrestrial frugivores, with the exception of two sites directly connected to the reference site. Our results indicate that the terrestrial mammal community in forests of Central Panama is currently degraded, even inside national parks. These data provide a baseline for evaluating the success of conservation efforts to prevent the Panamanian Isthmus to become a bottleneck for movement of animals.
\end{abstract}

Key words: community surveys; Darien; fragmentation; connectivity; evenness; species richness; Mesoamerican Biological Corridor. 


\section{Introduction}

The formation of the Isthmus of Panama 3 million years ago facilitated a massive exchange of animal and plant species between North and South America, a biogeographical event known as the Great American Interchange (Marshall et al. 1982). The land bridge contributed to Central America becoming the planet's third largest 'megadiversity hotspot', harbouring 5-12\% of the planet's biodiversity on just $0.5 \%$ of the land surface (Grandia 2007). Today, however, migration along the Isthmus of Panama may be more difficult for many organisms. The country of Panama has been experiencing rapid economic development, which has resulted in massive loss and fragmentation of natural habitat (Heckadon-Moreno 1993). Panama lost 14.3\% of its forest cover between 1990 and 2010, and just $43.7 \%$ of this narrow country remains forested (FAO 2010). Moreover, economic development, population growth, agricultural expansion, forest conversion and fragmentation, traffic and poaching pose an increasing threat to wildlife (Griffiths and van Schaik 1993; Heckadon-Moreno 1993; Wright et al. 2000). Anthropogenic pressure is especially intense in Central Panama, due to the presence and expansion of two major cities - Panama City and Colon - with associated infrastructure including the Panama Canal (Heckadon-Moreno 1993).

Economic development in the Canal watershed has led to dramatic changes of its ecosystems (Heckadon-Moreno 1993). Especially, large-bodied terrestrial mammals may be declining, as they are vulnerable to local extinction in fragmented landscapes because of their relatively large home ranges, small population sizes and persecution by humans (Crooks 2002; Kinnaird et al. 2003; Urquiza-Haas et al. 2011; Moreno et al. in press). However, quantitative studies on the presence and abundance of terrestrial mammals in this region are rare and consider small scales only (Ibáñez et al. 2002; MéndezCarvajal 2012). This is problematic as data on the status of biodiversity in Central Panama are essential for conservation programs aimed to restore the connectivity of forests for facilitating wildlife movement. The Mesoamerican Biological Corridor project (MBC), for example, seeks to establish a biological corridor for wildlife from Southern Mexico to Panama (Grandia 2007). 
An important reason why the current status of wildlife in Central Panama remains unclear is that many species of interest are secretive and/or nocturnal and therefore difficult to survey objectively by direct observation or line transects counts (Silveira et al. 2003). Over the past decade, however, camera-based surveys have become a feasible, reliable and non-invasive alternative method for surveying communities of rare and cryptic terrestrial mammals (Tobler et al. 2008; Ahumada et al. 2011; Kays et al. 2011). Camera-trap surveys can yield data on the relative abundance of species, as the number of instances at which animals of a species are photographed is positively correlated with that species' abundance (O'Connell et al. 2011).

In this study, we used camera-trap data to test the hypothesis that terrestrial mammal communities in the forests of Central Panama are degraded, having (1) lower species richness and evenness, and a higher index of defaunation and (2) a poor representation of large-bodied species, compared to "intact" reference communities. Moreover, we hypothesized that (3) degradation of mammal communities in Central Panama is greater for forest fragments than for national parks, and (4) greater towards the West, further away from the larger protected forests lying on the Eastern side of the Canal. We collected data from camera-trapping surveys from 15 forest sites across Central Panama, and two sites in the Darién NP in Eastern Panama, a forest relatively intact that qualifies as reference (Condit et al. 2001; Moreno 2006).

\section{Methods}

Study area

Panama lies in the moist tropics with an average annual temperature ranging from $22-31^{\circ} \mathrm{C}$. The dry season runs from late December to early May, and the annual rainfall amounts $1700-3000 \mathrm{~mm}$ on the Pacific and Atlantic coasts but increases with altitude to $6000 \mathrm{~mm}$ in the Darién (Ibáñez et al. 2002). At present, around half of the forest in Central Panama has been cleared (FAO 2010). Outside of the national parks, the area is a mosaic of both old-growth and secondary forest patches surrounded by plantations, grasslands and human settlements (Condit et al. 2001).The region is intersected by the Panama Canal, a busy shipping route that may constitute a barrier for many terrestrial species (Moreno et al. in press), and two highways that connect the cities of Colón and Panamá. Two biological 
corridors that have been proposed as part of the MBC project would run through this area (Fig. 1) (USAID 2009).

We surveyed 15 forest sites east and west of the Panama Canal, including large protected areas (national parks, nature reserves and a Nature Monument, henceforth referred to as "national parks") as well as forest fragments within the agricultural matrix that were scattered in between the protected sites (Fig. 1,Table 1). As reference sites for comparison, we used Cana and Pirre in the Darién NP, one of the largest protected areas in Mesoamerica, located on the far eastern side of Panama along the Colombian border, $<300 \mathrm{~km}$ from Central Panama. The park, listed as a Biosphere Reserve, contains the most diverse and species-rich terrestrial ecosystems of Central America and is relatively intact (Condit et al. 2001; Moreno 2006).

\section{Camera trap surveys}

Camera-trapping surveys were conducted as part of different projects with different objectives and thus different designs and protocols. All surveys used unbaited camera traps deployed during the dry season and accounted for minimum 500 trapping nights (Table 1) to have a sufficient sampling effort as it usually takes around 400 trap nights to record most of the common species in tropical forests (Tobler et al. 2008). The surveys in Darién were designed to estimate jaguar density, while the other surveys were designed to randomly capture any terrestrial mammal species. The 15 sites in Central Panama were surveyed with camera traps (Reconyx PC 900 Hyperfire - Reconyx, Inc, WI, USA) placed at 16-30 computer-generated points in grids. The surveys in the Barro Colorado Nature Monument (BCNM) and Soberania NP followed the protocol of the Tropical Ecology Assessment and Monitoring Network (TEAM Network 2011). The Darien sites were surveyed with 45 stations of cameras (Cuddeback Capture - Cuddeback, WI, USA) set up in pairs along trails and ridges. Cameras in large areas were placed in a subset of the area, while cameras in small fragments were set up in a way that the entire site was sampled (Table 1).

Photos from BCNM and Soberania NP were processed in DeskTEAM (Fegraus et al. 2011), photos from Darién NP and San Lorenzo NP were annotated in Excel 2007 (Microsoft Corporation, Redmond WA, USA), and photos from the other sites in Central Panama were processed in the 
ForestGEO camera-trapping database (as in Kays et al. 2011; http://www.forestGEO.si.edu). Photos were manually grouped into sequences that represented the same visit of an animal or group of animals (notably coatis Nasua narica and peccaries species Tayassu pecari and Pecari tajacu) in a 2 hour-interval, which triggered the same camera one or multiple times depending on movement speed and residence time. This filter assured that visit events were independent despite the fact that some species, especially the Central American agouti Dasyprocta punctata, can spend a longer time in the area around the camera. Animal identifications were based on Reid (2009). We excluded strictly arboreal mammal species (primates and Rothschild's porcupine Coendou rothschildi), species that are mostly aquatic or riverine (capybara Hydrochoerus isthmus and Neotropical river otter Lontra longicaudis), small species that are not systematically detected by the camera traps (mouse species and Marmosa robinsoni) and all bird species. We calculated the detection rates for species, a measure of relative abundance, as the number of visits photographed per 100 trap days. We assumed that for most species, the number of visits that the cameras recorded is proportional to the local density of the species, i.e. cameras will record a species more often where it is more abundant (O'Connell et al. 2011).

\section{Data analysis}

To account for differences in sampling effort when estimating species richness for each site, we generated sample-based rarefaction curves in EstimateS v.9.0 (Colwell 2013). Curves were fitted to deployments - i.e. a run of a camera trap at a single point within a site - and then rescaled to the number of animal detections in that deployment as given by the variable "individuals" in the output of EstimateS. We used the Jackknife 1estimator of species richness because it performs better with camera trapping data than do the Chao indices (Tobler et al. 2008), and gave the closest estimation to the total number of 30 species known for Darién (Reid 2009). Pielou's evenness index, a measure of diversity related to the relative abundance of species in a community was calculated using standard methods (Shannon and Weaver 1963). The index of defaunation (D) is a quantitative/weighted measure of dissimilarity between a focal assemblage of a given location and a reference assemblage that represents an unperturbed state (Giacomini \& Galetti 2013). We calculated D of each community 
in Central Panama with respect to two reference communities, i.e. Cana and Pirre, following the index

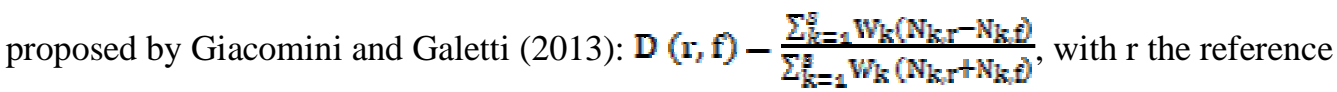

community i.e. Pirre or Cana, $f$ the focal community, i.e. the sites in Central Panama, $S$ the total number of species, $\mathrm{k}$ the particular species, $\mathrm{N}$ the occurrence (presence/absence) of species $\mathrm{k}$ in the reference and the focal community, $\mathrm{W}_{\mathrm{k}}$ the importance of a species $\mathrm{k}$ assigned by the body size $(\mathrm{kg})$ raised to the power of 0.75 (Table 2). Body size is a proxy for vulnerability to extinction and conservation concern (Giacomini \& Galetti 2013). An index close to the upper limit 1 indicates a higher defaunation where most species are absent in a focal community while an index close to 0 occurs when the two communities are similar and when little defaunation has occurred.

We used the $95 \%$ confidence intervals of each curve to test for differences in species richness between sites (Gotelli \& Colwell 2001; Colwell et al. 2004). Residuals of species evenness were normally distributed (Shapiro-Wilk $\mathrm{df}=15, \mathrm{p}=0.622$ ) so we used one-sample t-tests in SPSS 19 (SPSS Inc. 2007) to determine whether evenness was lower in Central Panama than at the two reference sites in Darién. Residuals of the defaunation indices were normally distributed when either Cana or Pirre were used as a reference site (Shapiro Wilk, $\mathrm{df}=15, \mathrm{p}_{\text {cana }}=0.495, \mathrm{p}_{\mathrm{pirr}}=0.507$ ) and Levene's tests confirmed homogeneity of variances $\left(\mathrm{F}_{\text {pirre }}=0.065, \mathrm{p}=0.937, \mathrm{~F}_{\text {cana }}=0.070, \mathrm{p}=0.933\right)$. We therefore conducted a one-way ANOVA and a Tukey-Kramer post-hoc test in SPSS to test whether the index of defaunation was different at a significant level of 0.05 between national parks and fragments east and west of the Panama Canal. The capture rate of each species, centered by species, was compared between sites with a Principal Component Analysis (PCA) on the species x sites matrix using the software CANOCO 5 (Braak \& Smilauer 2012) by square-root transforming detection rates.

\section{Results}

A total of 31 terrestrial mammal species from 15 families were recorded, of which only three were captured in all 17 sites: agouti, nine-banded armadillo and common opossum (Table 2). Species richness was highest in one reference site, Pirre $(\hat{\mathrm{S}}=27)$, followed by two national parks in the Canal 
area, $\mathrm{BCNM}$ and Soberania ( $\hat{\mathrm{S}}=23$ and $\hat{\mathrm{S}}=22$, respectively; Fig. 2A; Table 3). Richness was lowest in Cerro Cama (CCA: $\hat{\mathrm{S}}=14)$, a small fragment on the western side of the Panama Canal, and in one site of Agua Salud (AgSa3: $\hat{S}=15$; Fig. 2B; Table 3). Overall, small forest fragments tended to have fewer species per unit effort than did protected sites (Fig.2). Species richness was significantly higher at the reference site Pirre than all the other sites, as shown by non-overlapping confidence intervals of the species accumulation curves (Table 3), while richness was significantly lower for the fragments StDom and CCA than for Soberania and BCNM but not the other sites. The rest of the sites did not differ significantly from each other in terms of species richness.

Species evenness tended to be higher in the reference site Cana and at Cocobolo, and lowest in San Lorenzo and Barro Colorado (Table 3), mainly due to relatively high detection rates of agouti at the latter sites (Table 3). Compared to sites in central Panama, evenness was higher in Cana but lower in Pirre (One-sample T-test, $\mathrm{df}=14, \mathrm{t}_{\text {Cana }}=4.465, \mathrm{p}_{\text {Cana }}=0.001$ and $\left.\mathrm{t}_{\text {Pirre }}=2.144, \mathrm{p}_{\text {Pirre }}=0.05\right)$.

The indices of defaunation were different between the national parks and the fragments east and west when either Pirre or Cana were used as reference sites (ANOVA, $\mathrm{df}=2, \mathrm{~F}_{\text {Cana }}=7.221$, $\mathrm{p}_{\text {Cana }}$ $=0.009$ and $\left.\mathrm{F}_{\text {Pirre }}=8.101, \mathrm{p}_{\text {Pirre }}=0.006\right)($ Table 3). Specifically, there was no difference between the fragments east and west of the Panama Canal but the defaunation in the national parks of Central Panama was lower than in the forests fragments (Fig. 3A). The index of defaunation varied substantially at the same richness but tend to decrease with species richness $\left(R_{\text {Cana }}^{2}=0.45\right.$ and $R_{\text {Pirre }}^{2}=$ 0.43) (Fig. 3B).

Community composition varied widely among sites (Fig. 4). The first two axes of the ordination diagram explained $56.0 \%$ of the total variation in the community composition of terrestrial mammals among sites. The first axis (36.7\% of the total variation) explained the variation in species community structure among the protected sites in Panama, and was strongly related to the relative abundance of game species (i.e. lowland paca, collared peccary, white-tailed deer and red brocket deer) and species that are persecuted because of the damage they induce to crops (i.e. coati). Their abundance increased along the first axis and was highest in the larger protected sites of Central Panama (i.e. Soberania, San Lorenzo and especially Barro Colorado and Plantation road) and where 
large predators and frugivores were not detected. The second axis (17.3\% of the total variation) explained the differences between the small sites in Central panama and the larger, more remote sites in Portobelo and Darién, and was related to the abundance of two groups of species. The first group included tapir, white-lipped peccary, giant anteater, jaguar and puma, which are large indicator species that require large tracts of contiguous forest, and that are locally in danger of extinction. While relatively abundant in Darién, these species were not detected in Central Panama except at the two most remote sites, where they were rare. The second group consisted of small- to medium-sized species that are habitat generalists and are not actively targeted by hunters (e.g., rats, opossums and armadillos). These species were relatively abundant in the smaller, unprotected forest fragments.

\section{Discussion}

This study used camera-trapping surveys to assess the composition of terrestrial mammal communities in the forests of Central Panama, the narrowest and most disturbed part of the Isthmus of Panama, and a key area for conservation in the region. We found that most sites in Central Panama had lower species richness and a relatively poor representation of large-bodied species compared to the reference sites. These findings indicate that the terrestrial mammal community in forests of Central Panama is currently degraded, even inside national parks.

Our hypothesis that terrestrial mammal communities in the forests of Central Panama are degraded was partly supported by the survey data. As predicted, communities in Central Panama had lower species richness compared to the reference communities in Darién, and were less structurallycomplex revealing the rarity of top predators and large frugivores in most Central Panamanian sites. Large frugivores (i.e tapirs) were only detected on BCI, which is intensively patrolled by game wardens, whereas other indicator species were only detected in the more remote, protected sites that lie adjacent to the large tracts of forests that run continuously along the Atlantic coast towards Darién.

The patterns observed agree with tropical studies where species richness decreased in forest fragments (Turner 1996), smaller sites in the Brazilian Atlantic Forest (Chiarello 1999) and in sites surrounded with higher disturbance (Ahumada et al. 2011). Evenness was higher in Cana but lower in Pirre, in contrast to Ahumada et al. (2011) who did not find differences in evenness between sites with 
different sizes and disturbance degree. The index of evenness is related to the abundance of species in a community, and a low index of evenness thus indicates the dominance of one or several species. The abundance of the agouti was much higher than the other species in most sites with the exception of Cana, which could explain the low evenness values.

Second, we hypothesized that degradation of mammal communities would be greater for forest fragments than for national parks, and greater towards the West, further away from the larger protected forests blocks lying on the Eastern side of the Canal. These predictions were partially supported by the data. Most national parks had relatively high species richness and our results show a high heterogeneity in structure among wildlife communities throughout Central Panama. However, there was no difference between the fragments east and west of the Panama Canal; they were equally degraded. In general, small forest fragments were characterized by small-to medium sized mammals with smaller home ranges and that can therefore persist in these smaller disturbed habitats, just as Chiarello (1999) found in the Atlantic Forest in Brazil. In contrast, larger common species, i.e. the deer and collared peccary, were more frequently detected in sites East of the Canal that were relatively large and protected, or forest fragments adjacent to these protected areas. This was further corroborated by the index of defaunation which was higher in the fragments indicating that communities of Central Panama tended to become impoverished by loosing larger species similarly to what Giacomini and Galetti (2013) had already showed. Small fragments usually cannot sustain large vertebrates (Peres 2001) and bias of mammal communities towards smaller species is a well-known effect of fragmentation (Chiarello 1999; Kinnaird et al. 2003). Habitat loss and fragmentation also promote hunting by increasing forest accessibility to poachers who prefer to harvest medium-to-large sized herbivores and granivores (Peres 2001; Wright et al. 2000). Although illegal, hunting pressure is high throughout Central Panama (Wright et al. 2000; RM \& NM pers. obs.) including protected areas that are easily accessible (RM \& NM pers. obs.).

Hunting coupled with fragmentation may explain the absence or rarity of large vulnerable species such as tapir, white-lipped peccary, giant-anteater, jaguar and puma in Central Panama. Outside of BCI, tapirs are extremely rare in Central Panama and have not been reported for decades (Meyer et al. 2013). White-lipped peccaries require large areas of several thousand hectares to 
maintain breeding populations and are highly sensitive to hunting (Reyna-Hurtado et al. 2009), especially in Panama where they are the favored game species and have gone locally extinct in many areas (Moreno \& Meyer 2014). The elusive giant-anteater has never been reported in sites adjacent to the Canal, but was sighted in 2012 in Boquerón close to our sites in Santo Domingo (R. Morales pers. com.). Jaguars and pumas do still occur in Central Panama, though at a very low density as they have never been photographed in the protected sites adjacent to the Canal (i.e. Soberania, San Lorenzo, Barro Colorado), except for one individual that spent 6 months on BCI in 2009 (Willis 2009). However, sightings and tracks are sporadically reported by researchers and game wardens working in Barro Colorado and in Soberania, and by local people in the matrix of Central Panama (Moreno et al. in press). These individuals might be migrating through the landscape rather than being residents in the area, because they have very large home ranges and are heavily persecuted by people (Moreno et al. in press).

Our camera traps recorded two species that are relatively newcomers to Central Panama. The coyote, known from North America, was recorded in Pina, close to the Panama Canal. This species has already been reported more south at the border with the Darién Province (Mendéz-Carvajal \& Moreno 2014). The crab-eating fox, native to South America, was recorded next to a cleared area near an indigenous community in Darién, and along the Panama Canal in Limon. The two species are habitat generalists and are thus well adapted to survive in fragmented landscapes that may in fact have facilitated their range expansion (Faria-Corrêa et al. 2009; Méndez-Carvajal \& Moreno 2014).

Two key assumptions are underlying our analysis. The first is that all mammals found in our Darién surveys have originally occurred in Central Panama before any defaunation took place in historic years. Indeed, all species photographed in Darién, except for oncilla and giant anteater, were also photographed in our sites in Central Panama, although none of the surveys recorded all species in a single site. Moreover, these species are also present in Donoso, a primary forest near central Panama at the opposite side (Moreno unpub. data), and old studies report the presence of most species in Central Panama (Goldman 1920). The second assumption was that the surveys in the respective forests sites described the composition of the mammal communities in a sufficiently comparable manner, despite the fact that designs differed between surveys. We believe that the difference of camera traps 
settings (on/off-trail) between Darién and Central Panama - which may cause differences in detection of large felids that preferentially use trails (Harmsen et al. 2009) - was not a problem in our study, as on-trail camera-trapping surveys undertaken in Soberania and BCNM but not included in this study, confirm the rarity of large cats in Central Panama (Moreno and Willis, unpub. data). Also, the reference communities were logically positioned in the ordination results rather than being outliers. Variation in camera spacing should have had little impact on the results (Tobler et al. 2008) because in most sites the species accumulation curves reached an asymptote. Nevertheless, in the future, further standardizing the study design may help reducing variation in detection rates across surveys (cf. Sollmann et al. 2013).

Our study provides a baseline for the monitoring of mammal communities in Central Panama forests over time. Evaluating the mammal community on a regular basis with the surrounding development activities will help to evaluate the effectiveness of measures, if they are taken, to increase protection and restore connectivity to prevent the Panamanian Isthmus to become a bottleneck for movement of animals. Our study does not allow to identify the mechanisms underlying the degradation of mammal communities that we observed, but it is probable that hunting, forest degradation, physical barriers and isolation, or a combination of these are involved. Actions that could possibly lead to recovery would then include: 1) Enhance connectivity between parks and fragments, for example by implementing biological corridors and creating wildlife overpasses over the road network along the Canal to facilitate mammal movements and gene flow between forests now separated (Olsson et al. 2008); 2) Enhanced forest protection coupled with better education of local people to reduce poaching (Moreno et al. in press); 3) Reduce forest conversion and degradation, for example by implementing a program of payments for ecosystem services (Rodriguez 2014).

\section{Acknowledgments}

We thank the students of the University of Panama and the University of Wageningen and Van Hall Larenstein, the interns and fellows of STRI, the BCI game wardens, the policemen of Gamboa, and the Emberas of Pijibasal for field assistance; H. Rissanen, M. Roy and all local land owners for providing housing and access to forest fragments; the Ministerio de Ambiente, Smithsonian Tropical Research 
Institute (STRI), Primate Conservation Inc, and CREA for logistical support and permits; S. Valdez, M. Torres and C. Chang from MWH Panama for the data of San Lorenzo. The data of BCNM and Soberania were collected as part of the Tropical Ecology Assessment and Monitoring Network, a collaboration between Conservation International, the Missouri Botanical Garden, the Smithsonian Institution, and the Wildlife Conservation Society, and partially funded by these institutions, the Gordon and Betty Moore Foundation, and other donors. This study was partly funded by the Smithsonian Institution (Grand Challenges Award to PAJ), the Graduate school of Production Ecology and Resource Conservation (PAJ and HJE), the Jaguar Conservation Fund of Panthera (CKN, RM, ADC), APPC, and Fondo Darién/GEMAS (USA embassy/TNC/Ministerio de economia y finanzas/ANAM/Fundes/Panamcham/Fundacion Natura) (RM). Finally, we thank two anonymous reviewers for comments on a previous version of the manuscript.

\section{References}

Ahumada, J.A., Silva, C.E.F., Gajapersad, K., Hallam C., Hurtado, J., Martin E., McWilliam, A., Mugerwa, B., O'Brien, T., \& Rovero, F. (2011). Community structure and diversity of tropical forest mammals: data from a global camera trap network. Phiolosophical Transactions of the Royal Society B, 366, 2703-2711.

Braak, C.J.F., \& Smilauer, P. (2002). CANOCO reference manual and CanoDraw for Windows user's guide: software for canonical community ordination (version 4.5).

Chiarello, A.G. (1999). Effects of fragmentation of the Atlantic forest on mammal communities in south-eastern Brazil. Biological Conservation, 89, 71-82.

Colwell, R.K., Mao, C.X., \& Chang, J. (2004). Interpolating, extrapolating, and comparing incidencebased species accumulation curves. Ecology, 85, 2717-2727

Colwell, R. K. (2013). EstimateS: Statistical estimation of species richness and shared species from samples. Version 9. User's Guide and application published at: http://purl.oclc.org/estimates

Condit, R., Robinson, W.D., Ibáñez, R., Aguilar, S., Sanjur, A., Martínez, R., Stallard, R.F., García, T., Angehr, G.R., \& Petit, L. (2001). The status of the Panama Canal watershed and its biodiversity at the beginning of the 21st century. BioSciences, 51, 389-398.

Crooks, K.R. (2002). Relative sensitivities of mammalian carnivores to habitat fragmentation. Conservation Biology, 16, 488-502. 
Faria-Corrêa, M., Balbueno, R.A., Vieira, E.M., \& de Freitas, T.R.O. (2009). Activity, habitat use, density, and reproductive biology of the crab-eating fox (Cerdocyon thous) and comparison with the pampas fox (Lycalopex gymnocercus) in a Restinga area in the southern Brazilian Atlantic Forest. Mammalian Biology, 74, 220-229.

Fegraus, E.H., Lin, K., Ahumada, J.A., Baru, C., Chandra, S., \& Youn, C. (2011). Data acquisition and management software for camera trap data: A case study from the TEAM Network. Ecological Informatics, 6, 345-353.

Food and Agriculture Organization of the United Nations (2010) Global Forest Resources Assessment. ISBN 978-92-5-106654-6.

Giacomini, H.C., \& Galetti, M. (2013). An index for defaunation. Biological Conservation, 163, 3341.

Goldman, E.W. (1920). Mammals of Panama (with thirty-nine plates). Smithsonian Miscellaneous Collections 69. Published by the Smithsonian Instution, City of Washington, USA.

Gotelli, N.J., \& Colwell, R.K. (2001). Quantifying biodiversity: procedures and pitfalls in the measurement and comparison of species richness. Ecological letters, 4, 379-391.

Grandia, L. (2007). Between Bolivar and bureaucracy: the Mesoamerican Biological Corridor. Conservation and Society, 5, 478-503.

Griffiths, M., \& van Schaik, C.P. (1993). The impact of human traffic on the abundance and activity periods of Sumatran rain forest wildlife. Conservation Biology, 7, 623-626.

Harmsen, B.J., Foster, R.J., Silver, S., Ostro, L., \& Doncaster, C.P. (2009). Differential Use of Trails by Forest Mammals and the Implications for Camera-Trap Studies: A Case Study from Belize. Biotropica, 42, 126-133.

Heckadon Moreno, S. (1993). Impact of development on the Panama Canal environment. Journal of Interamerican Studies and World Affairs, 35, 129-149.

Ibáñez, R., Condit, R., Angehr, G., Aguilar, S., Garcia, T., MartÍnez, R, Sanjur., A, Stallard, R., Wright, S.J., \& Rand, A.S. (2002). An ecosystem report on the Panama Canal: monitoring the status of the forest communities and the watershed. Environmental Monitoring and Assessment, $80,65-95$.

Kays, R., Tilak, S., Kranstauber, B., Jansen, P.A., Carbone, C., Rowcliffe, M., Fountain, T., Eggert, J., $\&$ He, Z. (2011). Camera Traps as Sensor Networks for Monitoring Animal Communities. International Journal of Research and Reviews in Wireless Sensor Networks, 1, 19-29. 
Kinnaird, M.F., Sanderson, E.W., O’Brien, T.G., Wibisono, H.T., \& Woolmer, G. (2003).

Deforestation trends in a tropical landscape and implications for endangered large mammals.

Conservation Biology, 17, 245-257.

Marshall, L.G., Webb, S.D., Sepkoski, J.J., \& Raup, D.M. (1982). Mammalian evolution and the Great American Interchange. Science, 215, 1351-1357.

Mendez-Carvajal, P. (2012). Estudio de diversidad de mamiferos en cuatro habitats asociados a una plantacion de Teca (Tectona grandis) dentro de la cuenca del Canal de Panama, Las Pavas, Chorrera, Panama. Tecnociencia, 14, 55-83.

Mendéz-Carvajal, P., \& Moreno, R. (2014). Mammalia, Carnivora, Canidae, Canis latrans (Say, 1823): Actual distribution in Panama. Checklist, 10, 376-379.

Meyer, N., Moreno, R., \& Jansen, P. (2013). Distribution and conservation status of the Baird's tapir in Panama. Tapir Conservation, 30, 10-13.

Moreno, R. (2006). Parámetros poblacionales y aspectos ecológicos de los felinos y sus presas en Cana, Parque Nacional Darien, Panamá. National University of Costa Rica (MSc Thesis).

Moreno, R., \& Meyer, N. (2014). Distribution and conservation status of the white-lipped peccary (Tayassu pecari) in Panama. Suiform soundings, 13, 32-37.

Moreno, R., Bustamante, A., Méndez-Carvajal, P., \& Moreno, J. (In press). Jaguares en Panamá: Estado actual y conservacion. El jaguar en el Siglo XXI: La perspectiva Continental. CONABIO-Alianza WWF Telcel-Universidad Nacional Autónoma de México. México D.F.

O’Connell, A.F., Nichols, J.D., \& Karanth, K.U. (2011). Camera Traps in Animal Ecology: Methods and Analyses, first ed. Springer.

Olsson, M.P.O., Widén, P., \& Larkin, J.L. (2008). Effectiveness of a highway overpass to promote landscape connectivity and ovement of moose and roe deer in Sweden. Landscape and Urban Planning, 85, 133-139.

Peres, C.A. (2001). Synergistic Effects of Subsistence Hunting and Habitat Fragmentation on Amazonian Forest Vertebrates. Conservation Biology, 15, 1490-1505.

Peres, C.A. (2000). Effects of subsistence hunting on vertebrate community structure in Amazonian forests. Conservation Biology, 14, 240-353.

Reid, F.A. (2009). A field guide to the mammals of Central America and Southeast Mexico. Oxford University Press, USA. 
Reyna-Hurtado, R., Rojas-Flores, E., \& Tanner, G.W. (2009). Home Range and Habitat Preferences of White-Lipped Peccaries (Tayassu pecari) in Calakmul, Campeche, Mexico. Journal of Mammalogy, 90, 1199-1209.

Robinson, J.G., \& Redford, K.H. (1986). Body size, diet, and population density of Neotropical forest mammals. The American Naturalist,128, 665-680.

Rodriguez, C.M. (2014). Carbono, agua y jaguares nueva propuesta de pagos por servicios ambientales en Costa Rica. Conservacion de Felinos en America, Panthera.

Shannon, C.E., \& Weaver, W. (1963). The mathematical theory of communication. University of Illinois Press, USA.

Silveira, L., Jacomo, A.T.A., \& Diniz-Filho, J.A.F. (2003). Camera trap, line transect census and track surveys: a comparative evaluation. Biological Conservation, 114, 351-355.

Smith, F.A., Lyons, S.K., Ernest, S.K.M., Jones, K.E., Kaufman, D.M., Dayan, T., Marquet, P.A., Brown, J.H., \& Haskell, J.P. (2003). Body mass of late Quaternary mammals. Ecology, 84, 3403-3403.

Sollman, R., Mohamed, A., Samejima, H., \& Wilting, A. (2013). Risky business or simple solution Relative abundance indices from camera-trapping. Biological Conservation, 159, 405-412.

SPSS Inc. Released 2011. IBM SPSS for Windows, Version 19.0. Chicago, SPSS Inc.

TEAM (2011) Terrestrial Vertebrate Protocol Implementation Manual, v. 3.1. Tropical Ecology, Assessment and Monitoring Network, Center for Applied Biodiversity Science, Conservation International, Arlington, VA, USA.

Tobler, M., Carrillo-Percastegui, S., Leite Pitman, R., Mares, R., \& Powell, G. (2008). An evaluation of camera traps for inventorying large-and medium-sized terrestrial rainforest mammals. Animal Conservation, 11, 169-178.

Turner, I.M. (1996). Species loss in fragments of tropical rain forest: a review of the evidence. Journal of Applied Ecology,33, 200-209.

Urquiza-Haas, T., Peres, C.A., \& Dolman, P.M. (2011). Large vertebrate responses to forest cover and hunting pressure in communal landholdings and protected areas of the Yucatan Peninsula, Mexico. Animal Conservation, 14, 271-282.

USAID Panama. (2009). Marco conceptual y planes de accion de los corredores biologicos del Filo de Santa Rita y Campo Chagres para la conectividad de los Parques Nacionales Soberania y Chagres. Proyecto Conservacion de la Biodiversidad en la Cuenca del Canal. Unpublished report. 
Willis, J. (2009). Jaguars at the Crossroads of the Continents. Jaguar news, $28,3$.

Wright, S.J., Zeballos, H., Domínguez, I., Gallardo, M.M., Moreno, M.C., Ibáñez, R. (2000).

Poachers alter mammal abundance, seed dispersal, and seed predation in a Neotropical forest.

Conservation Biology, 14, 227-239. 
Table 1: Characteristics of the 15 study sites in Central Panama and the 2 reference sites in Darién, with specifications of camera trapping surveys conducted in these sites

\begin{tabular}{|c|c|c|c|c|c|c|c|c|}
\hline \multirow[b]{2}{*}{ Code } & \multirow[b]{2}{*}{ Name } & \multirow[b]{2}{*}{ Status } & \multirow[b]{2}{*}{$\begin{array}{l}\text { Size } \\
\left(\mathrm{km}^{2}\right)\end{array}$} & \multicolumn{5}{|c|}{ Sampling } \\
\hline & & & & Period & $\begin{array}{c}\text { Area covered } \\
\left(\mathrm{km}^{2}\right)\end{array}$ & No. stations & $\begin{array}{c}\text { Interspacing } \\
(\mathbf{k m})\end{array}$ & $\begin{array}{c}\text { Total effort } \\
\text { (days) }\end{array}$ \\
\hline \multicolumn{9}{|c|}{ Reference sites } \\
\hline CAN & Cana & NP & 5970 & $2005 / 06$ & 110 & 44 & $1-3.2$ & 2049 \\
\hline PIR & Pirre & NP & 5970 & 2014 & 73 & 44 & $0.8-1.5$ & 3372 \\
\hline \multicolumn{9}{|c|}{ Sites East of the Panama Canal } \\
\hline COC & Cocobolo & PA & 4 & 2013 & 1 & 16 & 0.33 & 603 \\
\hline PBO & Portobelo & NP & 349 & $2013 / 14$ & 1 & 29 & 0.33 & 766 \\
\hline StDom & Sant Domingo & PL & 0.8 & $2012 / 13$ & 0.8 & 31 & 0.03 & 695 \\
\hline SrLlor & Sierra Llorona & PL & 2.1 & $2012 / 14$ & 1 & 29 & 0.33 & 673 \\
\hline LIM & Limon & $\mathrm{PL}$ & 0.02 & $2012 / 13$ & 0.02 & 30 & 0.03 & 739 \\
\hline AgSa1 & Agua Salud 1 & PL & 0.3 & $2012 / 14$ & 0.3 & 30 & 0.03 & 798 \\
\hline AgSa2 & Agua Salud 2 & $\mathrm{PL}$ & 0.2 & $2012 / 14$ & 0.2 & 24 & 0.03 & 595 \\
\hline AgSa3 & Agua Salud 3 & $P L$ & 0.3 & 2012 & 0.3 & 16 & 0.03 & 575 \\
\hline SOB & Soberania & NP & 225 & $2011 / 12 / 13$ & 120 & 87 & 1.4 & 2864 \\
\hline PLA & Plantation Road & NP & 225 & $2013 / 14$ & 1 & 29 & 0.33 & 723 \\
\hline \multicolumn{9}{|c|}{ Sites West of the Panama Canal } \\
\hline EMP & Nuevo Emperador & PL & 0.4 & $2013 / 14$ & 0.4 & 29 & 0.1 & 583 \\
\hline BCNM & Barro Colorado & NM & 54 & $2011 / 12 / 13$ & 54 & 87 & 1.4 & 2937 \\
\hline SanLo & San Lorenzo & NP & 97 & 2012 & 25 & 24 & $0.3-0.5$ & 624 \\
\hline CCA & Cerro Cama & $P L$ & 0.1 & $2013 / 14$ & 0.1 & 30 & 0.03 & 610 \\
\hline PIN & Pina & $\mathrm{PL}$ & 0.02 & $2013 / 14$ & 0.02 & 26 & 0.03 & 529 \\
\hline
\end{tabular}

$\mathrm{NP}=$ National park; $\mathrm{PL}=$ Forest fragment in a private land; $\mathrm{NM}=$ Nature Monument; $\mathrm{PA}=$ Private protected area; $\mathrm{NR}=\mathrm{Nat}$ re Reserve. Area covered is the size of the camera trap survey. Interspacing is the distance in $\mathrm{km}$ between the cameras. Total effort is the total number of camera days. 
Table 2: Terrestrial mammal species recorded by camera traps across 17 forest sites in Panama, their diet, body size, size, and the number of sites where they were recorded

\begin{tabular}{|c|c|c|c|c|c|c|c|}
\hline & \multirow[b]{2}{*}{ Species } & \multirow[b]{2}{*}{ Common name } & \multirow[b]{2}{*}{ Diet } & \multirow[b]{2}{*}{$\begin{array}{c}\text { Body } \\
\text { size (kg) }\end{array}$} & \multirow[b]{2}{*}{$\begin{array}{l}\text { Size } \\
\text { class }\end{array}$} & \multicolumn{2}{|c|}{ No. sites recorded } \\
\hline & & & & & & Darién & Central Panama \\
\hline \multicolumn{8}{|l|}{ DIDELPHIMORPHIA } \\
\hline \multirow[t]{3}{*}{ Didelphidae } & Metachirus nudicaudatus & Brown four-eyed opossum & 10 & 0.4 & $\mathrm{~s}$ & 1 & 8 \\
\hline & Philander opossum & Gray four-eyed opossum & 10 & 0.7 & $\mathrm{~s}$ & 0 & 8 \\
\hline & Didelphis marsupialis & Common opossum & FO & 1.4 & $\mathrm{~s}$ & 2 & 15 \\
\hline \multicolumn{8}{|l|}{ CINGULATA } \\
\hline \multirow[t]{2}{*}{ Dasypodidae } & Cabassous centralis & Northern naked-tailed armadillo & MY & 3.3 & M & 0 & 9 \\
\hline & Dasypus novemcinctus & Nine-banded armadillo & 10 & 407 & M & 2 & 15 \\
\hline \multicolumn{8}{|l|}{ PILOSA } \\
\hline \multirow[t]{2}{*}{ Myrmecophagidae } & Tamandua mexicana & Northern tamandua & MY & 5.5 & M & 1 & 12 \\
\hline & Myrmecophaga tridactyla & Giant Anteater & MY & 36 & $\mathrm{~L}$ & 1 & 0 \\
\hline \multicolumn{8}{|l|}{ RODENTIA } \\
\hline Cuniculidae & Cuniculus paca & Lowland paca & FG & 8.3 & $\mathrm{~L}$ & 2 & 14 \\
\hline Dasyproctidae & Dasyprocta punctata & Central American agouti & FG & 3.1 & $\mathrm{M}$ & 2 & 15 \\
\hline \multirow[t]{2}{*}{ Echimyidae } & Hoplomys gymnurus & Armored rat & FO & 0.4 & $\mathrm{~S}$ & 1 & 12 \\
\hline & Proechimys semispinosus & Tome's spiny rat & FG & 0.4 & $\mathrm{~s}$ & 2 & 11 \\
\hline Sciuridae & Sciurus granatensis & Red-tailed squirrel & FG & 0.3 & $\mathrm{~s}$ & 2 & 14 \\
\hline \multicolumn{8}{|l|}{ LAGOMORPHA } \\
\hline Leporidae & Sylvilagus brasiliensis & Forest rabbit & $\mathrm{HZ}$ & 1 & $\mathrm{~s}$ & 2 & 6 \\
\hline \multicolumn{8}{|l|}{ CARNIVORA } \\
\hline \multirow[t]{2}{*}{ Canidae } & Cerdocyon thous & Crab-eating fox & CA & 5.9 & M & 2 & 1 \\
\hline & Canis latrans & Coyote & CA & 12.8 & $\mathrm{~L}$ & 0 & 2 \\
\hline \multirow[t]{6}{*}{ Felidae } & Leopardus tigrinus & Oncilla & CA & 2.2 & $M$ & 1 & 0 \\
\hline & Leopardus wiedii & Margay & CA & 3.6 & $M$ & 2 & 5 \\
\hline & Puma yagouaroundi & Jaguarundi & CA & 6.5 & $\mathrm{~L}$ & 1 & 10 \\
\hline & Leopardus pardalis & Ocelot & CA & 11.1 & $\mathrm{~L}$ & 2 & 13 \\
\hline & Puma concolor & Puma & CA & 46.8 & $\mathrm{~L}$ & 2 & 2 \\
\hline & Panthera onca & Jaguar & CA & 76.6 & $\mathrm{~L}$ & 2 & 1 \\
\hline \multirow[t]{2}{*}{ Mustelidae } & Galictis vittata & Greater grison & CA & 3.2 & $M$ & 1 & 3 \\
\hline & Eira barbara & Tayra & FO & 4.3 & $M$ & 2 & 13 \\
\hline \multirow[t]{3}{*}{ Procyonidae } & Nasua narica & White-nosed coati & FO & 4.3 & $M$ & 1 & 14 \\
\hline & Procyon cancrivorus & Crab-eating racoon & FO & 5.7 & $M$ & 1 & 10 \\
\hline & Procyon lotor & Northern racoon & FO & 5.5 & $M$ & 0 & 1 \\
\hline \multicolumn{8}{|l|}{ PERISSODACTYLA } \\
\hline Tapiridae & Tapirus bairdii & Baird's tapir & $\mathrm{FH}$ & 260 & $\mathrm{~L}$ & 2 & 1 \\
\hline \multicolumn{8}{|l|}{ ARTIODACTYLA } \\
\hline \multirow[t]{2}{*}{ Cervidae } & Mazama temama & Red brocket deer & $\mathrm{FH}$ & 22.8 & $\mathrm{~L}$ & 2 & 7 \\
\hline & Odocoileus virginianus & White-tailed deer & $\mathrm{HB}$ & 41.2 & $\mathrm{~L}$ & 0 & 6 \\
\hline \multirow[t]{2}{*}{ Tayassuidae } & Pecari tajacu & Collared peccary & FO & 19.8 & $\mathrm{~L}$ & 2 & 10 \\
\hline & Tayassu pecari & White-lipped peccary & $\mathrm{FH}$ & 33.8 & $\mathrm{~L}$ & 2 & 1 \\
\hline
\end{tabular}

Diet class was taken from Robinson and Redford (1986): CA: carnivore, FH: frugivore-herbivore, FG: frugivore-granivore, FO: frugivore-omnivore, HB: herbivore-browser, HZ: herbivore-grazer, IO: insectivore-herbivore, MY: myrmecophage. Body size was taken from Smith et al. (2003), and size class follow the classification of Peres (2000): S: small, M: medium, L: large. 
Table 3: Observed and estimated species richness and its significance difference using the $95 \%$ confidence intervals, evenness and index of defaunation of the terrestrial mammal communities recorded in camera trapping surveys in 2 sites of Darién and 15 sites of Central Panama, ranked east to west. Sites with different letters present significantly different species richness, while letters shared in common between the sites indicate no significant difference in species richness.

\begin{tabular}{|c|c|c|c|c|c|c|c|c|}
\hline \multirow[b]{2}{*}{ Site } & \multicolumn{4}{|c|}{ Species richness } & \multirow[b]{2}{*}{$\begin{array}{c}\text { Sig. } \\
\text { Difference }\end{array}$} & \multirow[b]{2}{*}{$\begin{array}{l}\text { Shannon } \\
\text { Evenness }\end{array}$} & \multicolumn{2}{|c|}{$\begin{array}{c}\text { Index of } \\
\text { defaunation }\end{array}$} \\
\hline & Observed & Jack 1 & Lower $\mathrm{Cl}$ & Upper Cl & & & Cana & Pirre \\
\hline CAN & 18 & 20.92 & 15.26 & 20.74 & $a b$ & 0.78 & - & - \\
\hline PIR & 26 & 26.98 & 25.21 & 26.79 & C & 0.63 & - & - \\
\hline $\mathrm{COC}$ & 17 & 18.88 & 15.48 & 18.52 & $a b$ & 0.83 & 0.35 & 0.42 \\
\hline РBO & 15 & 15.97 & 10.13 & 19.87 & $a b$ & 0.71 & 0.39 & 0.43 \\
\hline StDom & 14 & 14.00 & 14.00 & 14.00 & $a$ & 0.77 & 0.66 & 0.70 \\
\hline SrLlor & 14 & 15.93 & 9.02 & 18.98 & $a b$ & 0.64 & 0.50 & 0.56 \\
\hline LIM & 17 & 20.87 & 13.52 & 20.48 & $a b$ & 0.64 & 0.59 & 0.65 \\
\hline AgSa1 & 19 & 21.9 & 16.26 & 21.74 & $a b$ & 0.72 & 0.40 & 0.47 \\
\hline AgSa2 & 17 & 19.88 & 11.76 & 22.24 & $a b$ & 0.70 & 0.54 & 0.60 \\
\hline AgSa3 & 13 & 14.88 & 11.17 & 14.83 & $a b$ & 0.75 & 0.51 & 0.57 \\
\hline SOB & 20 & 21.98 & 18.1 & 21.9 & $b$ & 0.66 & 0.37 & 0.44 \\
\hline PLA & 14 & 15.93 & 9.02 & 18.98 & $a b$ & 0.67 & 0.44 & 0.50 \\
\hline EMP & 17 & 19.12 & 12.29 & 21.58 & $a b$ & 0.70 & 0.46 & 0.53 \\
\hline BCNM & 20 & 22.97 & 17.23 & 22.77 & $b$ & 0.54 & 0.11 & 0.19 \\
\hline SanLo & 16 & 19.83 & 11.54 & 20.46 & $a b$ & 0.48 & 0.37 & 0.44 \\
\hline $\mathrm{CCA}$ & 12 & 13.93 & 6.94 & 17.06 & $a$ & 0.74 & 0.69 & 0.73 \\
\hline PIN & 16 & 21.77 & 10.32 & 21.68 & $a b$ & 0.63 & 0.57 & 0.63 \\
\hline
\end{tabular}

Bold sites are protected. $\mathrm{Cl}=95 \%$ confidence interval 


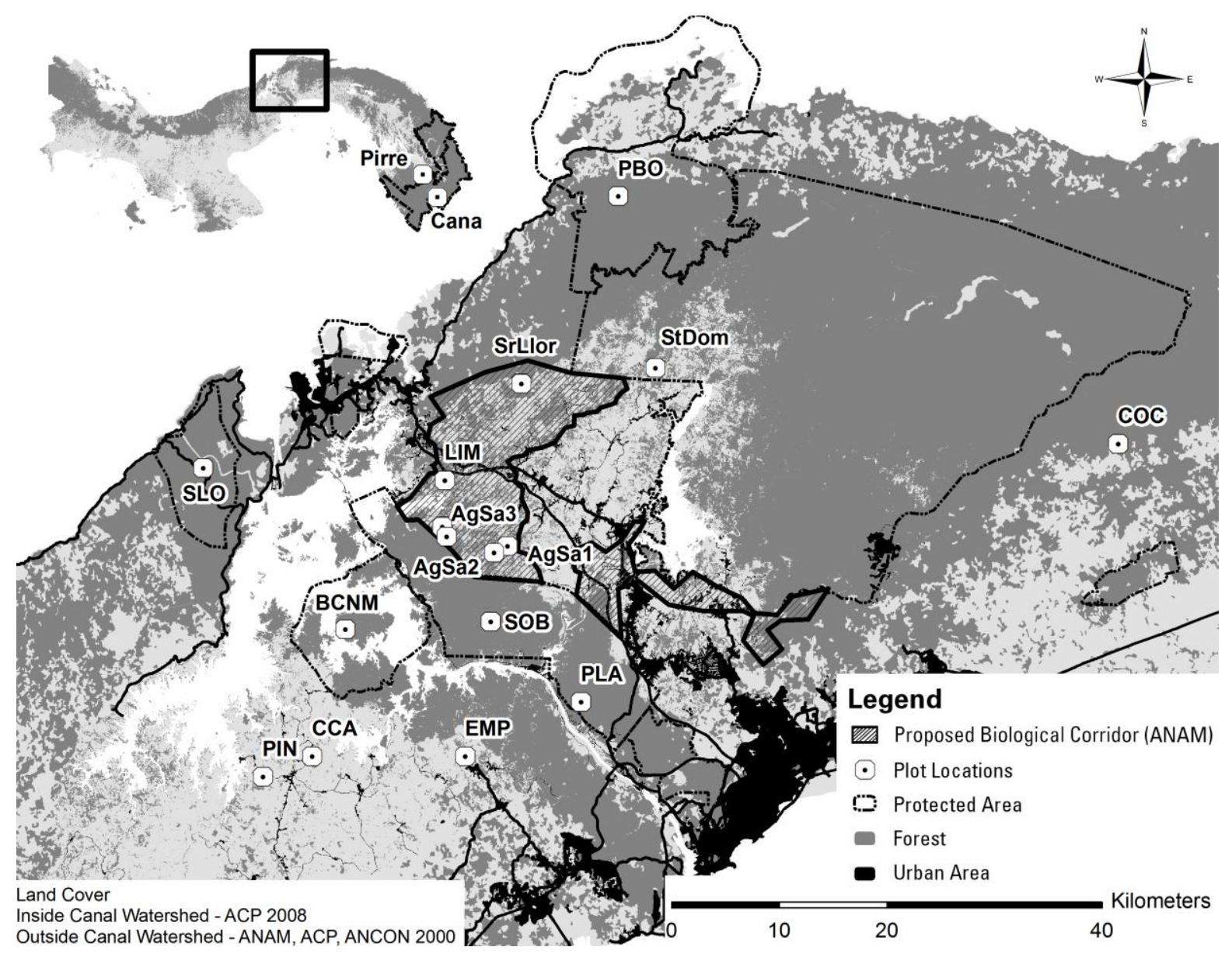

Figure 1: Location of the 17 sites where camera trapping surveys were conducted. See Table 1 for site codes.
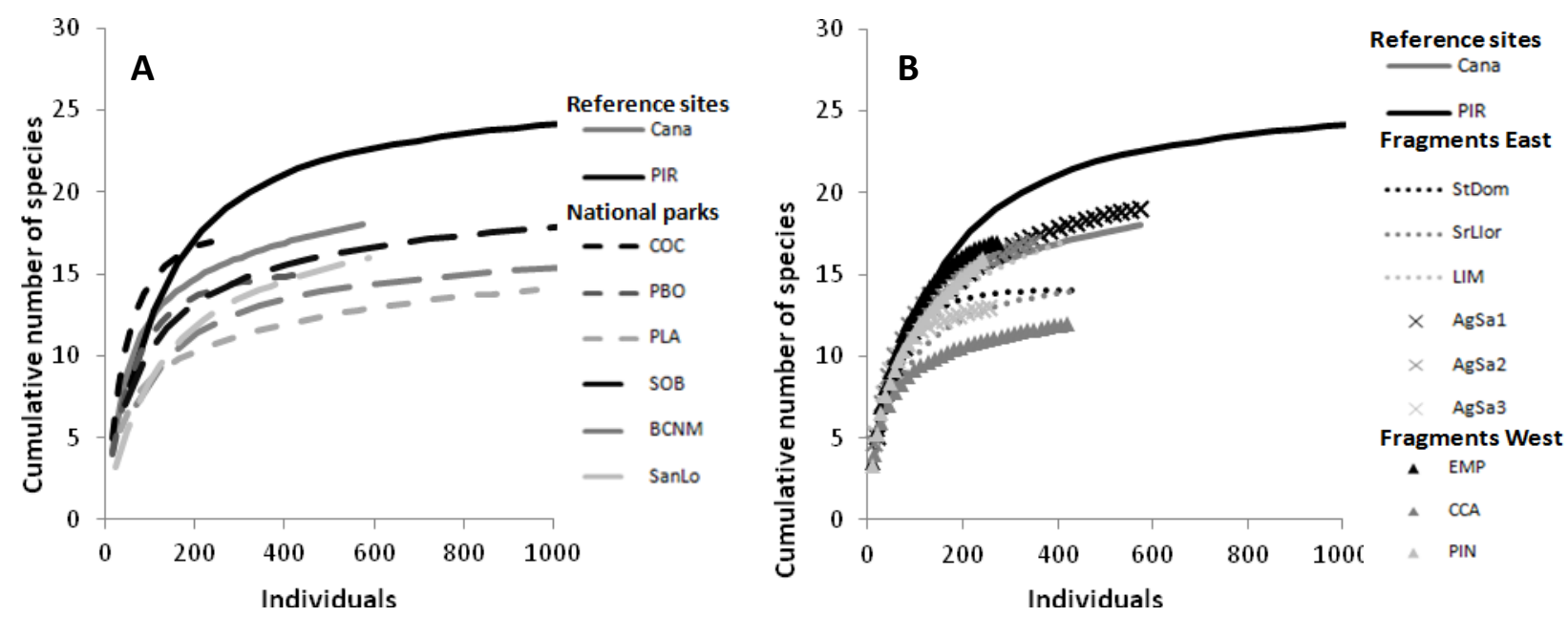

Figure 2: Sample-based rarefaction curves, based on camera-trapping data of 15 sites in Central Panama (National parks - A, and forest fragments - B) and two reference sites in Darién. See table 1 for site codes. 

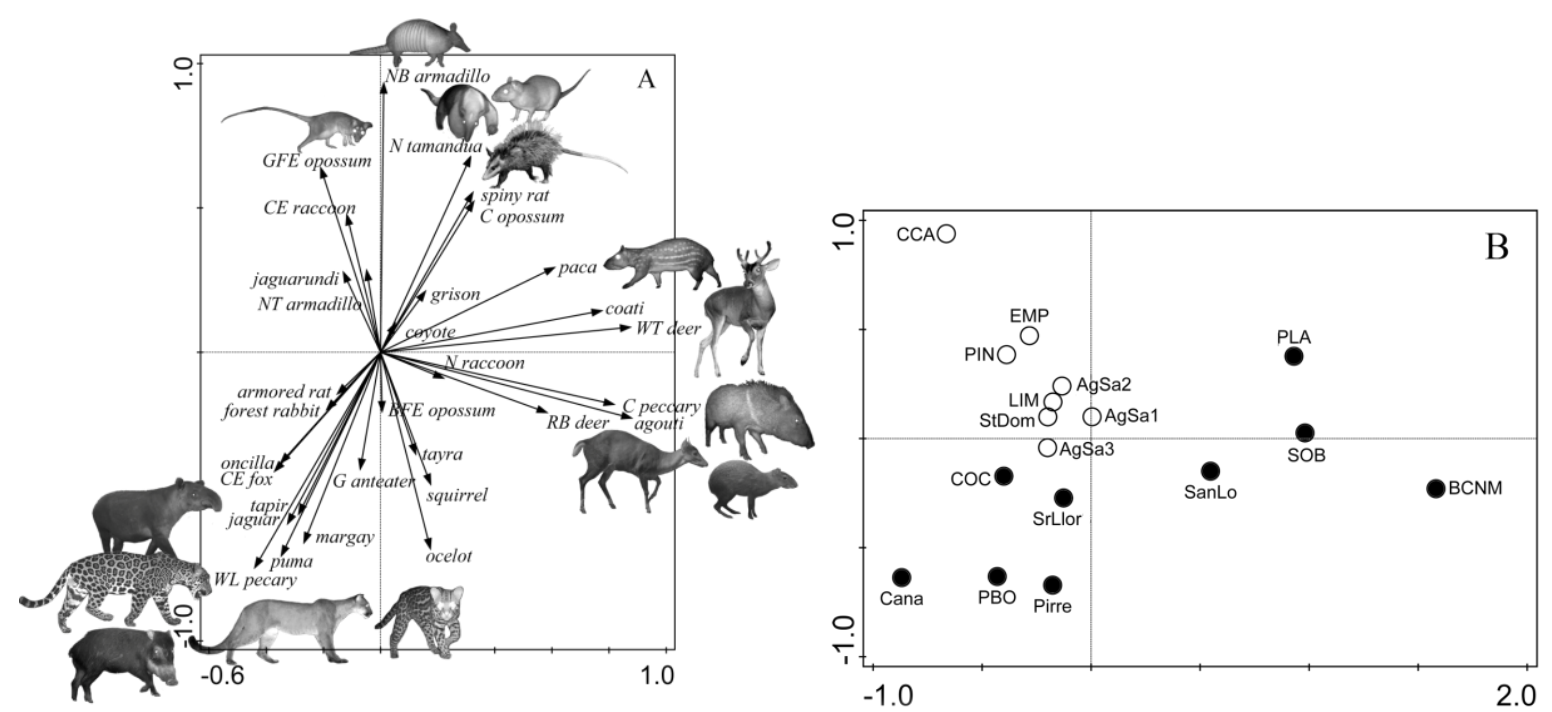

Figure 4: Results of a Principal Component Analysis of terrestrial mammal communities, based on capture rates by camera traps, at 15 forest sites in Central Panama and two 2 reference sites in Darién, for species (A) and sites (B). Arrows in (A) indicate the direction of maximum change in relative abundance across the ordination plot, where arrow length is proportional to the change. Black circles in (B) represent sites that are protected, and open circles represent forest fragments. See table 1 for site codes. The distances between sites indicate their similarity in terms of species composition and abundance.
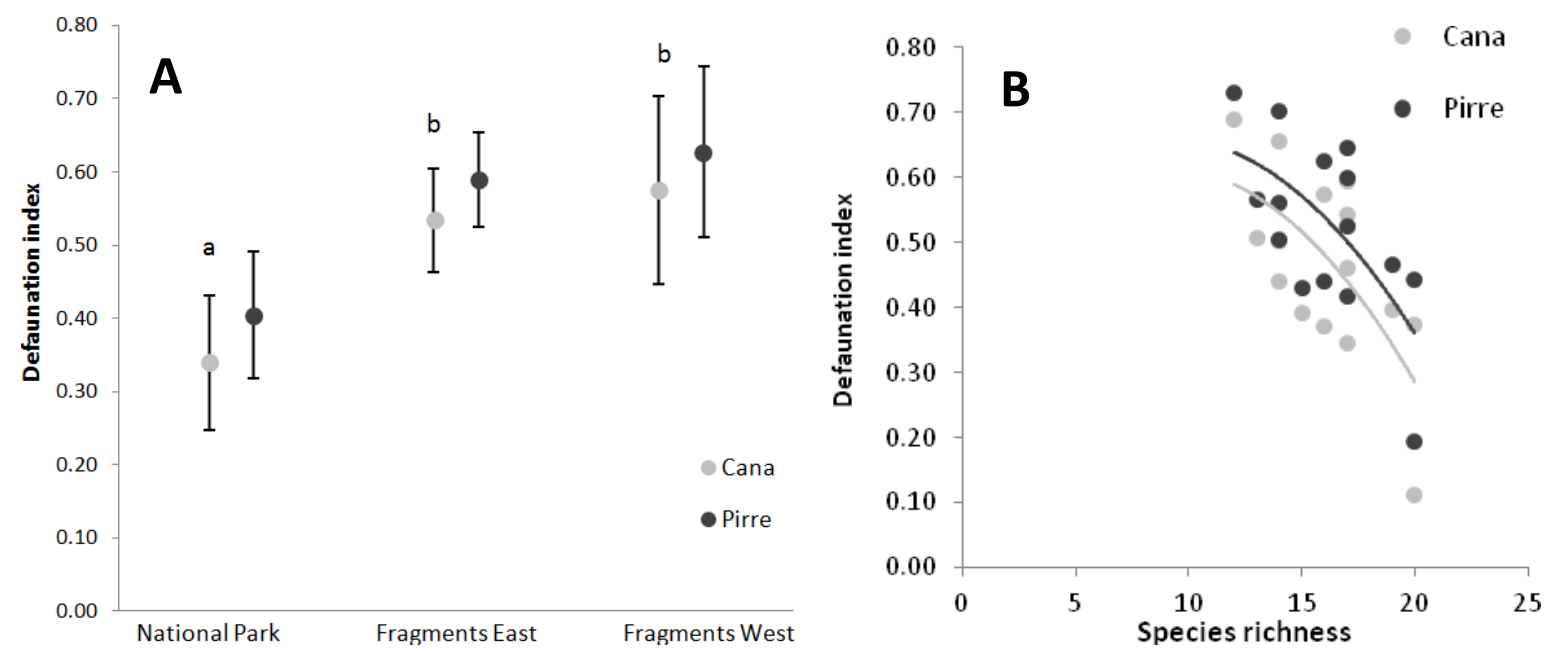

Figure 3: Mean defaunation index (D) and their error bars based on body size in mammal communities of Central Panama with respect to reference communities in Pirre and Cana in Darién (A) and as a function of species richness (B). 